\title{
A Talent Cultivation Model for Improving the Innovation Ability of College Students in Scientific Research
}

\author{
https://doi.org/10.3991/ijet.v15i18.16745 \\ Yanming Qi, Jingui Wang $(\bowtie)$ \\ Hebei University of Engineering, Handan, China \\ 513995261 dqq. com
}

\begin{abstract}
The innovation ability of college students in scientific research is constrained by multiple factors. What is worse, the current talent training model in colleges faces many defects. To solve these problems, this paper aims to develop a talent cultivation model that effectively enhances the innovation ability of college students in scientific research. Firstly, the problems with the current talent cultivation model were analyzed, and then the evaluation indicator system was improved for the innovation ability of college students in scientific research. Next, entropy weight method and gray system theory were integrated to create an evaluation model that quantifies the innovation ability of college students in scientific research. On this basis, several strategies were put forward to improve the said ability. The research results help to effectively enhance the innovation ability of college students in scientific research, and optimize the talent cultivation model in colleges and universities.
\end{abstract}

Keywords-Innovation ability in scientific research, colleges students, talent cultivation, evaluation model.

\section{Introduction}

With the continuous development and advancement of modern society, the demand for senior talents is becoming increasingly urgent. Higher education plays a very important role in the training of senior talents [1-3], especially in the fast-developing 21 st century, an era of knowledge and talents, there is a greater need for talents with innovation ability in scientific research; as a result, cultivating college students with innovation ability in scientific research has gradually become an important part of higher education, and it is also an inevitable process for the transformation of higher education from test-oriented education to quality-oriented education; moreover, it also has an important promotive effect on improving the college students' comprehensive qualities [4-6]. Therefore, how to improve college students' innovation ability in scientific research has gradually become a hot topic in the research of higher education. Kuo et al. studied how to enhance the learning motivation and creativity of college students through the courses of STEM interdisciplinary PBL human-computer interaction system design and development [7]. Rejeb and Roussel took the creative workshop and manufacturing laboratory of technological universities in North Africa as 
examples to research and analyze the issue of college students' innovative learning [8]. Li et al. analyzed the problems existing in the cultivation of medical students' innovation ability in scientific research and gave corresponding countermeasures [9]. Peng et al. discussed how to promote the cultivation of students' innovation ability based on the opening of research labs in universities [10]. Wang et al. discussed and analyzed how to cultivate the innovation ability of college students majored in scientific engineering in the context of new engineering disciplines [11]. Xie explored how to cultivate college students' innovation ability based on scientific research projects [12]. Gui studied how to enhance college students' innovation ability based on scientific research practice [13]. Sharma et al. discussed how to motivate the scientific research spirit and passion of college students majored in science and engineering disciplines [14].

However, existing studies concerning how to improve college students' innovation ability in scientific research mostly focus on strategic analysis, while in terms of the implementation mode of the cultivation of college students' innovation ability in scientific research and the corresponding evaluation model, there's still much room for further research. In particular, since different scholars have different perspectives on these issues, their understanding of the improvement of college students' innovation ability in scientific research vary as well, which has resulted in certain limitations in the application of the research results. To this end, based on a summary of existing research results, this paper further discusses and analyzes the improvement of the talent cultivation model of college students' innovation ability in scientific research.

The content of this paper includes 5 parts. The first part summarizes the problems existing in the research of college students' innovation ability in scientific research; the second part analyzes the influencing factors and constraints of the improvement of college students' innovation ability in scientific research; the third part constructs an improved evaluation system and an evaluation model for the college students' innovation ability in scientific research; the fourth part discusses the cultivation strategies and modes for improving college students' innovation ability in scientific research; the fifth part gives the conclusion.

\section{Influencing Factors and Constraints of the Improvement of College Students' Innovation Ability in Scientific Research}

Through investigation and analysis, this paper summarizes the influencing factors of the improvement of college students' innovation ability in scientific research, the specific contents are as follows:

\subsection{Uneven government support for scientific research and imperfect research platforms in colleges and universities}

At present, the government's support for scientific research in colleges and universities is uneven. Key schools have plenty funds while ordinary schools receive relatively few research funding. In order to promote education fairness, it is necessary to 
gradually regulate and improve the research budget system and give full play to the government's role in the investment of basic research funding in colleges and universities. At present, although some colleges have provided opportunities for the scientific research and innovation of students, for the massive college student group, there're still certain limitations. The scientific research platforms in colleges and universities are important guarantees for improving college students' innovation ability in scientific research. The construction of the research platforms includes hardware and software construction, wherein the hardware construction includes research labs, instruments and equipment, and scientific research teams, etc. The research platforms take their own development as the orientation, and constantly strengthen and expand themselves. Software system is corresponding to the hardware system, as the hardware system is being improved and strengthened continuously, the software system seems to be relatively weak.

\subsection{Single path for the scientific research and innovation of college students}

In colleges and universities, the forms for college students to participate in scientific research activities are limited, reviewing existing literatures and writing research papers are the main forms, and there are few applications for practical research and scientific research programs. When college students encounter scientific research problems, their primary method is to refer to library literatures and electronic resources, however, for some schools, the construction of library and digital information is far from satisfying the requirements of the students. In addition, scientific research programs are the main way for college students to participate in scientific and technological innovation, but some schools have not paid enough attention to this, they have only taken innovation and starting a business as part of the employment guidance, while ignored the explanation of theoretical knowledge, resulting in that college students know little about innovation. Only by combining theory with practice can we better trigger college students' innovation consciousness. At present, college students generally lack practical experience in scientific research, which leads to that their willingness to participate in scientific research programs is not very strong.

\subsection{Insufficient motivation for the scientific research and innovation of college students}

The scientific research and innovation of college students often requires certain research interest of students and the support of a scientific research atmosphere. However, at present, the academic atmosphere in some schools is not very good. On the one hand, the school's publicity for scientific innovation is not enough, students do not have much channels to acquire such information; on the other hand, although college students have realized the importance of scientific innovation to their own growth and development, due to the lack of perseverance and motivation, the difficulties and resistance they encountered in scientific research activities cannot be solved in time, which usually make them shrink back at the sight of scientific research. Therefore, injecting continual impetus for college students to participate in scientific 
research and innovation is an urgent problem to be solved for cultivating their innovation ability in scientific research. In addition, a sound scientific research innovation reward and punishment mechanism will undoubtedly provide a huge impetus for the innovation of college students, and material rewards and spiritual satisfaction will stimulate their innovation potential.

\subsection{Incomplete system for the scientific research and innovation of college students}

To cultivate college students, the higher education schools should follow the principle of combining teaching with the scientific research practice; scientific research and teaching are inseparable, the two have the relationship of the "source" and the "flow". Scientific research has speculative feature, which can enhance the innovation ability of college students, and teaching can improve their reserves of the latest knowledge. Teaching knowledges and educating people are the primary tasks of colleges and universities; however, teaching and scientific research are mutually promotive and reinforcing; to a certain extent, the teaching quality of colleges and universities depends on high-quality scientific research. Integrating scientific research into teaching can enhance the innovation spirit of college students, improve the scientific research level of the teachers, and it is helpful for teachers to enrich the teaching content in a timely manner, so that college students can get to know the cutting-edge research results as soon as possible; this provides a latest theoretical support for college students to participate in teachers' projects or various competitions, and how to perfect the system for the scientific innovation of college students is a very important research content.

\subsection{Superficial professional knowledge and theoretical foundation of college students and limited research time}

At present, due to the influence of club activities, teachers' teaching level, students' self-control ability, and their lack of interest in the teaching content, the phenomenon of skipping classes is frequent. The weak professional knowledge reserve often makes it difficult for college students to get started in scientific research, and they often lack confidence in participating in scientific research activities. Interest is the best teacher, however, not every student is interested in scientific research. Colleges and universities should cultivate college students' interest in their majors, constantly urge them to learn the professional theoretical knowledge, and consolidate the theoretical knowledge in the scientific research practice. Although many colleges have set up professional experimental courses to support college students' scientific research practice, most of the outcomes of the practice links are known, students just passively perform the experiments, and this method cannot effectively enhance their innovation ability. Guiding students to participate in their supervisors' research programs, cultivating their ability in independent problem-solving, and deepening their understanding and mastery of professional knowledge are effective ways to enhance their inno- 
vation ability in scientific research, and these are important research contents for higher education researchers.

\section{Evaluation System and Model for College Students' Innovation Ability in Scientific Research}

Through the above analysis, we can see that the cultivation of college students' innovation ability in scientific research is restricted by many influencing factors. To effectively enhance college students' innovation ability in scientific research, it is necessary to well solve the problems of college students' scientific innovation knowledge accumulation, the formation of scientific innovation thinking, the cultivation of scientific innovation behaviors, and the training of scientific innovation learning ability, etc. For this purpose, we need to make effective evaluation and analysis on college students' innovation ability in scientific research, and find out the weak links in their innovation ability on this basis, and then implement strategies for existing problems, thereby forming a corresponding talent cultivation model.

\subsection{Construction of the evaluation system for college students' innovation ability in scientific research}

This paper holds that, in order to effectively evaluate college students' innovation ability in scientific research, the evaluation needs to be conducted based on four standards: learning ability, innovative thinking, integration ability and innovation achievements. In accordance with the scientific, objective, comprehensive and operable principles of college students' scientific innovation ability evaluation indicator selection, this paper selected corresponding evaluation indicators under different criteria and formed an integrated evaluation system for college students' innovation ability in scientific research.

In terms of the evaluation of college students' scientific research and innovation, the learning ability indicator mainly reflects college students' abilities in learning, absorbing, and transforming the newly acquired knowledge, it includes evaluation indicators such as their ability in independent learning, ability in research literature retrieval, ability in hot research topic absorption and digestion, and ability in research task regulation and control, and ability in scientific research practice (including experiments, system development and scientific exploration activities conducted in the purpose of deepening the scientific research works). The innovative thinking indicator mainly reflects college students' abilities and levels in scientific thinking and research perspectives, it includes evaluation indicators such as the ability to discover scientific research problems, the ability to analyze scientific research problems, the ability to solve scientific research problems, the ability to expand scientific research problems, and the ability to apply scientific knowledge. The integration ability indicator mainly reflects college students' abilities and levels in professional knowledge crossover and integration, it includes evaluation indicators such as the ability in cross-discipline innovation, ability in teamwork, ability to complete research tasks, ability in research 
paper writing, and ability to express scientific research problems, etc. The innovation achievement indicator mainly reflects college students' achievements in scientific research and innovation, it includes evaluation indicators such as the number of scientific innovation programs independently undertaken by college students, the number of provincial and ministerial-level and above scientific research programs participated by college students, number of times college students participating in provincial and ministerial-level and above science and technology contests, number of times college students receiving rewards in provincial and ministerial-level and above science and technology contests, number of high-quality research papers published by college students, the number of applied or authorized patents of college students, and the quality of academic dissertation written by college students.

\subsection{Processing of evaluation indicators of college students' innovation ability in scientific research}

As can be seen from the evaluation system constructed above, there are many types of evaluation indicators for college students' innovation ability in scientific research, and different evaluation indicators have different evaluation dimensions, therefore, these indicators need to be standardized. In order to make the expression more adaptable, this paper assumes that there are a total of $m$ objects in the evaluation of college students' innovation ability in scientific research, and there are a total of $n$ evaluation indicators; for the $\mathrm{i}$-th evaluation object, the initial value of the $\mathrm{j}$-th evaluation indicator is $v_{i j}=\left[v_{i j}(a), v_{i j}(b)\right], v_{i j}(a) \leq v_{i j}(b)$.

If the $\mathrm{j}$-th evaluation indicator is a benefit-type indicator, then the corresponding standardized value is:

$$
\begin{aligned}
& u_{i j}=\left[u_{i j}(a), u_{i j}(b)\right] \\
& =\left[\frac{v_{i j}(a)-v_{i j}(a)}{\max _{1 \leq i \leq m} v_{i j}(b)-\min _{1 \leq i \leq m} v_{i j}(a)}, \frac{v_{i j}(b)-\min _{1 \leq i \leq m} v_{i j}(a)}{\max _{1 \leq i \leq m} v_{i j}(b)-\min _{1 \leq i \leq m} v_{i j}(a)}\right]
\end{aligned}
$$

If the $\mathrm{j}$-th evaluation indicator is a cost-type indicator, then the corresponding standardized value is:

$$
\begin{aligned}
& u_{i j}=\left[u_{i j}(a), u_{i j}(b)\right] \\
& =\left[\frac{\max _{1 \leq i \leq m} v_{i j}(b)-v_{i j}(b)}{\max _{1 \leq i \leq m} v_{i j}(b)-\min _{1 \leq i \leq m} v_{i j}(a)}, \frac{\max _{1 \leq i \leq m} v_{i j}(b)-v_{i j}(a)}{\max _{1 \leq i \leq m} v_{i j}(b)-\min _{1 \leq i \leq m} v_{i j}(a)}\right]
\end{aligned}
$$

After standardization, all evaluation indicators have the same metrics and all values are between $0-1$, in such case, there's no difference in the evaluation indicators, which can improve the reliability of the evaluation results. 


\subsection{Weights of evaluation indicators of college students' innovation ability in} scientific research based on the entropy weight method

Since different evaluation indicators have different importance, they should be assigned to different weights. Entropy, as an effective measure for the ordered state analysis of disordered information in complex systems, has been widely applied in the engineering field [15-24]. Therefore, based on the entropy weight method, this paper determines the corresponding weights through the values of the evaluation objects with respect to the evaluation indicators, so as to make the evaluation results more objective.

The values of $m$ evaluation objects with respect to $n$ evaluation indicators constructed the evaluation matrix $U$ of the entropy weight method, namely:

$$
\mathbf{U}=\left[\begin{array}{ccccc}
u_{11} & \cdots & u_{1 j} & \cdots & u_{1 n} \\
\vdots & \vdots & \vdots & \vdots & \vdots \\
u_{i 1} & \cdots & u_{i j} & \cdots & u_{i n} \\
\vdots & \vdots & \vdots & \vdots & \vdots \\
u_{m 1} & \cdots & u_{m j} & \cdots & u_{m n}
\end{array}\right]
$$

Then the information entropy corresponding to the $\mathrm{j}$-th evaluation indicator is:

$$
E_{j}=-\frac{1}{\ln m} \sum_{i=1}^{M}\left(\left(u_{i j} / \sum_{i=1}^{m} u_{i j}\right) * \ln \left(u_{i j} / \sum_{i=1}^{m} u_{i j}\right)\right)
$$

Accordingly, the weight of the $\mathrm{j}$-th evaluation indicator is:

$$
w_{j}=\frac{1-E_{j}}{\sum_{j=1}^{n}\left(1-E_{j}\right)}
$$

It can be seen that: $0 \leq w_{j} \leq 1, w_{1}+\cdots+w_{j}+\cdots+w_{n}=1$.

\subsection{Implementation of the evaluation model of college students' innovation ability in scientific research based on gray relational analysis}

According to the gray system theory [25-29], the value range for the gray ideal indicator of $m$ evaluation objects with respect to the $\mathrm{j}$-th evaluation indicator is:

$$
u_{j}=\left[u_{j}(a), u_{j}(b)\right]=\left[\max _{1 \leq i \leq m} u_{i j}(a), \max _{1 \leq i \leq m} u_{i j}(b)\right]
$$

As a result, the value sequence of the gray ideal indicator of the evaluation of college students' innovation ability in scientific research is formed, namely: 


$$
\mathbf{u}=\left\{u_{1}, u_{2}, \cdots, u_{j}, \cdots, u_{n-1}, u_{n}\right\}
$$

Then, the maximum distance between the i-th evaluation object with respect to the $\mathrm{j}$-th evaluation indicator and the gray ideal indicator value sequence $\mathrm{u}$ is:

$$
\Delta D_{\max }=\max _{1 \leq i \leq m} \max _{1 \leq j \leq n}\left|u_{j}-u_{i j}\right|
$$

where, $\left|u_{j}-u_{i j}\right|$ represents the fuzzy distance between the two.

Correspondingly, the minimum distance between the i-th evaluation object with respect to the $j$-th evaluation indicator and the gray ideal indicator value sequence $u$ is:

$$
\Delta D_{\min }=\min _{1 \leq i \leq m} \min _{1 \leq j \leq n}\left|u_{j}-u_{i j}\right|
$$

According to the gray relational analysis method, the gray relational coefficient between the $\mathrm{i}$-th evaluation object with respect to the $\mathrm{j}$-th evaluation indicator and the gray ideal indicator value sequence $u$ is:

$$
\gamma_{i j}=\frac{\Delta D_{\min }+\rho * \Delta D_{\max }}{\left|u_{j}-u_{i j}\right|+\rho * \Delta D_{\max }}
$$

where, $\rho$ is identification coefficient of gray relational analysis, $\rho \in[0,1]$, its value generally takes $\rho=0.5$.

The indicator weights are obtained based on the entropy weight method, the comprehensive weighted gray relational degree between the $\mathrm{i}$-th evaluation object and the gray ideal indicator value sequence $u$ is:

$$
\sigma_{i}=\sum_{j=1}^{n}\left(w_{j} * \gamma_{i j}\right)
$$

According to the size of the comprehensive weighted gray relational degree $\sigma_{i}$, the level of college students' innovation ability could be determined; the greater the value of $\sigma_{i}$, the stronger the innovation ability; a smaller $\sigma_{i}$ value indicates insufficient innovation ability, then targeted countermeasures need to be adopted to enhance the innovation ability of college students.

\section{Cultivation Strategies and Models for Improving College Students' Innovation Ability in Scientific Research}

This paper holds that the improvement of college students' innovation ability in scientific research is not a job that can be done overnight, but a systematic project that needs to be implemented and optimized from multiple aspects. 
4.1 Enhance college students' interest in scientific research, arouse their enthusiasm for participating in scientific research and innovation activities.

The first step for the construction of the scientific research and innovation activity system is to explore college students' interest in scientific research and guide them to actively participate in scientific research and innovation activities. However, college students tend to put their learning focus on classroom learning, they generally do not have the ability to carry out scientific research and innovation practice independently. Targeting at this issue, the schools can carry out a series of academic activities progressively, such as symposiums with famous teachers, or report meetings on hot research topics in the professional fields; with academic conferences or activities as the carrier, schools could point out the directions for college students to participate in scientific research and innovation activities. The interest and values of contemporary college students exhibit a diversified and complicated trend, therefore, in the whole process of these activities, schools must thoroughly grasp the learning characteristics and weak links of students at all stages, and guide them to actively participate in scientific research and innovation activities with scientific research tasks as the driving force.

\subsection{Cultivate college students' innovative thinking in scientific research and promote the crossover and integration of professional courses}

Cultivating college students' innovative thinking is helpful for the application and optimization of their professional knowledge system, it is an important link for promoting their innovation ability in scientific research. Innovative thinking is closely related to the improvement of the intensity, density and synergy of scientific research and innovation activities of college students. In the classrooms, we should pay attention to the training of college students' divergent thinking ability, guide them to think independently and build a reasonable knowledge structure and a rich knowledge base; for college students, the more the professional knowledge reserves, the more fluent their scientific research thinking. To this end, in terms of curriculum setting of college students' professional courses, the relevance with the discipline should be taken as the criteria, and comprehensive courses should be increased accordingly, so that a diversified curriculum system could be set up, and colleges students can contact more interdisciplinary subjects; in this way, we could guide college students to adopt a correct attitude toward interdisciplinary subjects, stimulate their interest, expand their knowledge scope, and thereby enabling them to think about scientific research problems from different angles.

\subsection{Cultivate college students' scientific research and innovation methods and strengthen their innovation ability in scientific research}

Enhancement in the scientific research ability enables college students to solve scientific research problems more accurately and quickly, which is of great significance 
to the successful completion of the scientific research tasks. To this end, in the process of cultivating the scientific research qualities of college students, schools can increase courses concerning the scientific research and innovation methods and pay attention to experimental and practical courses, moreover, we should provide more opportunities for college students to conduct profound observation and join in relevant scientific research groups, so that they could apply their professional knowledge in a more flexible way, and have a deep understanding of the application situation and framework of the scientific research and innovation methods. In addition, by inviting well-known scientific research teams in the field and combining with scientific research programs and application cases, the schools can teach college students about the scientific research and innovation methods, and the existing problems and deficiencies, so that during the research process, they can integrate theory with practice; moreover, more attention should be paid to the scientific research openness and methodological guidance of college students, so as to enhance their communication ability in scientific research.

\subsection{Pay attention to the scientific research and innovation practice of college students and build a mechanism for the full participation of supervisors}

In the process of college students' scientific research and innovation, supervisors are playing a very important role; they not only help to optimize college students' thinking mode in scientific research, but also help them strengthen their ability to tackle scientific research problems. Therefore, in this process, under the guidance of the supervisors, we need to pay attention to the value of the scientific research programs, the balance of resource integration, the effectiveness of teamwork, and the rationality of outcome incubation, etc. In terms of the cultivation of college students' innovation ability in scientific research, according to the relevance of the majors and disciplines, colleges and universities should select supervisors with different academic backgrounds and outstanding innovation consciousness and abilities in a targeted manner, form supervisor groups for the scientific research programs of college students, and jointly supervise and guide the scientific research programs of college students. As individual college students, they can rely on the supervisor experimental platforms and scientific research team resources to carry out scientific research and innovation practice; moreover, with the help of a sound college student teachingresearch system, we can ensure that their professional course learning could catch up with the requirement of the times and the progress of the most advanced research, thereby effectively promoting college students' innovation ability in scientific research.

4.5 Coordinate the scientific research and innovation process of college students and build a platform for their scientific research and innovation practice

Colleges and universities need to encourage college students to actively participate in scientific research programs and practice, including various types of college student 
science and technology competitions, academic exchange activities, and the supervisors' research projects, etc. From the perspective of discipline subdivision, colleges and universities need to coordinate college students' scientific research and innovation process concerning the research content of their majors and form a comprehensive and systematic system for college students' innovation ability in scientific research. In order to support the construction of the system more effectively, from inside, schools should enhance their ability in discipline construction, from the outside, they also need to build innovation platforms among the schools, the research institutions, and the enterprises, and form a school-enterprise united innovation mechanism. On the one hand, we should promote the construction of the college student scientific research and innovation platforms, strengthen the mutual communication of the requirements of schools and enterprises, and provide multi-level research directions for college students, so that the research programs in which college students participate could be more targeted, valuable, and time-sensitive. On the other hand, promoting the communication and learning between college students and different-level researchers not only enhances the exchange of scientific research questions among college students with different professional backgrounds, but also makes it easier to rationally allocate the scientific research and innovation resources and enhance the social recognition of college students' scientific research results, which is conductive to the incubation of college students' scientific research achievements, to some extent, this also helps to trigger college students' enthusiasm and initiative in scientific research and innovation.

\section{Conclusion}

The main research results of the paper are reflected in the following aspects:

1. The paper analyzed the deficiencies and problems existing in the cultivation of college students' innovation ability in scientific research. Then on this basis, it constructed a more targeted evaluation system for college students' innovation ability in scientific research, which provided theoretical support for the evaluation of college students' innovation ability in scientific research.

2. Based on entropy weight method and gray relational analysis, this paper constructed a model for the evaluation of college students' innovation ability in scientific research. The model has clear physical meaning and strong objectivity, which provided a quantified calculation model for the effective evaluation of college students' innovation ability in scientific research.

3. The paper proposed a series of strategies for the cultivation of college students' innovation ability in scientific research, which further improved the current cultivation modes and provided effective support for improvement of college students' innovation ability in scientific research. 


\section{References}

[1] Ciesielkiewicz, M., Wisser, W., Rozells, D. (2019). International perspectives on ePortfolios in higher education: Case studies from Asia, North America and Europe, International Journal of Emerging Technologies in Learning, 14(21), 96-109. https://doi. org/10.3991/ijet.v14i21.11048

[2] Yaisawarng, S., Ng, Y.C. (2014). The impact of higher education reform on research performance of Chinese universities. China Economic Review, 31: 94-105. https://doi.org/ 10.1016/j.chieco.2014.08.006.

[3] Tao, J.G., Zhang, Y., Liao, L.L. (2020). An empirical study on students' innovation influencing factors of college ability in scientific research. Journal of Higher Education Management, 14(3): 104-112. https://doi.org/10.13316/j.cnki.jhem.20200507.011.

[4] Liu, Z.H., Tian, Q.L., Wang, J., Miao, N. (2019). Research on realization path of improving innovation ability of college students. Journal of Changsha Aeronautical Vocational and Technical College, 19(4): 8-12. https://doi.org/10.13829/j.cnki.issn.16719654.2019.04.03.

[5] Huang, M.H., Chen, D.Z. (2017). How can academic innovation performance in university-industry collaboration be improved. Technological Forecasting and Social Change, 123: 210-215. https://doi.org/10.1016/j.techfore.2016.03.024.

[6] Jin, M., Wang, X.L., Wei, L.H., Yan, M.T., Liu, L., Bai, G.Y., Yang, Y.T. (2019). Design and practice of inquiry experiment based on undergraduate students' ability of scientific research and innovation. Experimental Technology and Management, 36(1): 213-216. https://doi.org/10.16791/j.cnki.sjg.2019.01.050 .

[7] Kuo, H.C., Tseng, Y.C., Yang, Y.T.C. (2019). Promoting college student's learning motivation and creativity through a STEM interdisciplinary PBL human-computer interaction system design and development course. Thinking Skills and Creativity, 31: 110. https://doi.org/10.1016/j.tsc.2018.09.001.

[8] Rejeb, H.B., Roussel, B. (2018). Design and innovation learning: Case study in north African engineering universities using creativity workshops and fabrication laboratories. Procedia CIRP, 70: 331-337. https://doi.org/10.1016/j.procir.2018.03.263.

[9] Li, B.Q., Zhang, L., Qi, F., Bi, H.D., Wu, X.G. (2019). The problems and Countermeasures of the cultivation of scientific research innovation ability of medical students. Education Modernization, 6(86): 56-57. https://doi.org/10.16541/j.cnki.20958420.2019.86.024.

[10] Peng, Y., Wang, L.P., Li, T., Wang, Y.Y., Yan, J., Wu, X., Xie, J.Y., Zhu, Y.M. (2019). Research On the role of the opening of scientific research laboratories in Colleges and universities in promoting the cultivation of students' innovation ability. Education Modernization, 6(69): 99-100, 149. https://doi.org/10.16541/j.cnki.2095-8420.2019.69.041

[11] Wang, Y.G., Cheng, Z.L., Kou, Q.M., Sun, P., Yang, W. (2019). Cultivation of scientific research and innovation ability of mechanical engineering undergraduates for new engineering. Education Modernization, 6(60): 4-6. https://doi.org/10.16541/j.cnki.2095$\underline{8420.2019 .60 .002}$.

[12] Xie, H. (2019). The exploration and practice of cultivating the innovative ability of college students in combination with scientific research projects. Education Modernization, 6(88): 37-39. https://doi.org/10.16541/j.cnki.2095-8420.2019.88.015 .

[13] Gui, X.H. (2018). Improving college students' innovative ability based on scientific research practice. Experimental Technology and Management, 35(2): 21-25. http://dx.doi.org/10.16791/j.cnki.sjg.2018.02.006 . 
[14] Sharma, K., Sharma, Y., Mantri, A., Sharma, R. (2020). Inculcating the spirit and passion for research among Engineering students at Undergraduate level. Procedia Computer Science, 172: 488-493. https://doi.org/10.1016/j.procs.2020.05.162.

[15] Han, B., Liu, H., Wang, R. (2015). Urban ecological security assessment for cities in the Beijing-Tianjin-Hebei metropolitan region based on fuzzy and entropy methods. Ecological Modelling, 318: 217-225. https://doi.org/10.1016/j.ecolmodel.2014.12.015.

[16] Ouchtati, S., Chergui, A., Mavromatis, S., Aissa, B., Rafik, D., Sequeira J. (2019). Novel method for brain tumor classification based on use of image entropy and seven Hu's invariant moments. Traitement du Signal, 36(6), 483-491. https://doi.org/10.18280/ts.3606 $\underline{02}$

[17] Allahverdyan, A.E., Galstyan, A., Abbas, A.E., Struzik, Z.R. (2018). Adaptive decision making via entropy minimization. International Journal of Approximate Reasoning, 103: 270-287. https://doi.org/10.1016/j.ijar.2018.10.001.

[18] Cui, Z., Wang, Y.X. (2019). Denoising of seismic signals through wavelet transform based on entropy and inter-scale correlation model. Instrumentation Mesure Métrologie, 18(3), 289-295. https://doi.org/10.18280/i2m.180309

[19] Chukwumaobi, O., Akinlabi, E.T., Njoku, H.O. (2020). Selection of phase change material for improved performance of Trombe wall systems using the entropy weight and TOPSIS methodology. Energy and Buildings, 217: 1-10. https://doi.org/10.1016/j.enbuild.2020.109 967.

[20] Murugan, S., Kulanthaivel, G., Ulagamuthalvi, V. (2019). Selection of test case features using fuzzy entropy measure and random forest. Ingénierie des Systèmes d'Information, 24(3), 261-268. https://doi.org/10.18280/isi.240306

[21] Alao, M.A., Ayodele, T.R., Ogunjuyigbe, A.S.O., Popoola, O.M. (2020). Multi-criteria decision-based waste to energy technology selection using entropy-weighted TOPSIS technique: The case study of Lagos, Nigeria. Energy, 201: 1-14. https://doi.org/10.1016/j.e nergy.2020.117675

[22] Shao, Z.H., Zhong, Z.X., Lin, W.Z. (2018). Reliability analysis and matpower simulation of IEEE14 node based on mixed entropy measure. European Journal of Electrical Engineering, 20(5-6), 573-588. https://doi.org/10.3166/ejee.20.573-588

[23] Delgado, A., Romero, I. (2016). Environmental conflict analysis using an integrated grey clustering and entropy-weight method: A case study of a mining project in Peru. Environmental Modelling \& Software, 77: 108-121. https://doi.org/10.1016/j.envsoft.2015. $\underline{12.011 .}$.

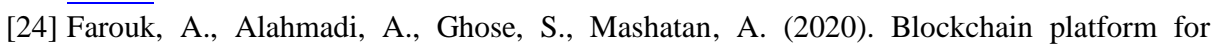
industrial healthcare: Vision and future opportunities. Computer Communications, 154, 223-235. https://doi.org/10.1016/j.comcom.2020.02.058

[25] Soota, T. (2020). Multi-response optimization of machining parameter for Zircaloy by response surface methodology and grey relation analysis. Materials Today: Proceedings, 21: 1544-1550. https://doi.org/10.1016/j.matpr.2019.11.084.

[26] Lee, C., Lee, J.W., Ryu, S.G., Oh, J.H. (2019). Optimum design of a large area, flexure based XY $\theta$ mask alignment stage for a 12-inch wafer using grey relation analysis. Robotics and Computer-Integrated Manufacturing, 58: 109-119. https://doi.org/10.1016/j.r cim.2019.02.005.

[27] Wakchaure, K.N., Thakur, A.G., Gadakh, V., Kumar, A. (2018). Multi-objective optimization of friction stir welding of aluminium alloy 6082-T6 Using hybrid TaguchiGrey relation analysis-ANN method. Materials Today: Proceedings, 5(2): 7150-7159. https ://doi.org/10.1016/j.matpr.2017.11.380 
[28] Ikram, M., Sroufe, R., Rehman, E., Shah, S.Z.A., Mahmoudi, A. (2019). Do quality, environmental, and social (QES) certifications improve international trade? A comparative grey relation analysis of developing vs. developed countries. Physica A: Statistical Mechanics and its Applications, 545: 1-15. https://doi.org/10.1016/j.physa.2019.123486.

[29] Liu, M., Zhang, Q. (2019). Evaluation of student performance with predicted learning curve based on grey models for personalized tutoring, International Journal of Emerging Technologies in Learning, 14(13), 157-171. https://doi.org/10.3991/ijet.v14i13.9880

\section{$7 \quad$ Authors}

Yanming Qi was born in Handan city, Hebei Province in November 1980. She graduated from Hebei Normal University with a bachelor's degree in 2003 and Hebei University with a master's degree in 2010. Since 2003, I had been working in School of Humanity and Law, Hebei University of Engineering, engaged in Chinese language and literature, ideological and political education and scientific research for college students. In 2015, I was appointed as an associate professor. Yanming Qi had published more than 30 papers, presided over more than 10 provincial and ministerial scientific research projects, published 3 books, and won 5 provincial and ministerial awards. Articles published in the theoretical edition of Guangming Daily were reprinted in large quantities. I am good at ideological and political research and public opinion control of college students.

Jingui Wang was born in Yi Country, Baoding city, Hebei Province in September 1980. She graduated from Hebei Agricultural University with a bachelor's degree in 2003 and a master's degree in 2006. Since 2006, She had been working in School of Water Conservancy and Hydroelectric Power, Hebei University of Engineering, engaged in water conservancy and ideological and political education and scientific research for college students. In 2019, She was appointed as an associate professor. Jingui Wang had published 8 academic papers on ideological and political education, including 3 core journals, 5 provincial journals, written 1 monograph and edited 1 textbook. Besides, she had presided over 7 provincial scientific research projects, 1 municipal scientific research project and 2 university-level scientific research projects over the past five years. She is good at ideological and political education, mental health education, innovation and entrepreneurship education of college students.

Article submitted 2020-06-17. Resubmitted 2020-07-23. Final acceptance 2020-07-25. Final version published as submitted by the authors. 